\title{
Speed Control Using Fuzzy Controller for a Four Switch Sensorless BLDC Motor
}

\author{
NibaShoby \\ EEE Dept, NSSCE \\ Palakkad, India
}

\author{
DeepikaVasanthakumar, \\ Assistant Professor, \\ EEE Dept, NSSCE \\ Palakkad, India
}

\author{
Anupama P K \\ Assistant Professor, \\ EEE Dept, NSSCE \\ Palakkad, India
}

\begin{abstract}
Brushless Direct Current (BLDC) motors are highly efficient motors with high reliability and a longer life span. The advent of sensor less technology has improved the performance and reliability of BLDC motor drives. This work is to analyze a drive system for BLDC motor with Four-Switch Three-Phase Inverter (FSTPI). Back Electromotive Force (EMF) Zero Crossing Detection (ZCD) method is used to estimate the rotor position. Speed control of motor is achieved by using Fuzzy Logic Controller (FLC) based closed loop control system. The Simulation was carried out using MATLAB software and motor the performance was analyzed with FLC for motor speed regulation.
\end{abstract}

Keywords:-Brushless Direct Current Motor, Electromotive Force , Four switch Three Phase Inverter, Back EMF, Zero Crossing Detection, Fuzzy Logic Controller.

\section{INTRODUCTION}

Permanent Magnet Motors are widely used in many applications in electric appliances and industrial automation because of their high efficiency and power density. With respect to the shape of their Back EMFs, PM motors can be classified into Permanent Magnet AC synchronous (PMAC) motor (with sinusoidal back EMF) and Brushless DC (BLDC) Motor (with trapezoidal back EMF). The excitation of a PMAC motor is given by a three phase current of sinusoidal nature. BLDC motor is usually excited by currents with quasi-square shaped waveform.

Nowadays significance of BLDC motors are high due to advantages like high efficiency and reliability, longer life span quick response, low noise operation, high torque to weight ratio etc.. .

BLDC motors are normally excited by six switch inverters. But higher number of switches increases the system cost and make it more complex. Thus arouse a need to switch to a system with lesser number of switches and the four switch inverter fed BLDC motor was introduced. The main advantages of four switch inverters are lesser number of switches and lower conduction losses [2][3].
Two types of controlling techniques are used for working of BLDC motors. These are sensor based control technique and low cost sensor less control techniques[4]. These motors have large applications in computer hardware systems, automated industrial systems, fans, pumps and blowers, electric vehicles, aerospace applications etc.

There are two commonly used sensor less control techniques [5][6]. There are many control techniques for sensor less control of BLDC Motors. One of such method is back emf based position sensing. Another method which requires high speed processors, does position approximation using various motor parameters. As the second method is costly the first method is most commonly used. [7],[8],[9].

Compared to the conventional controller technologies like P, PI and PID[10] controllers, one of the successful controller technology based on Fuzzy logic control is found to be more advantageous for the control of complex systems. [11],[12] . Fuzzy logic based controllers are low cost controllers which can cover a wide range of operating conditions.

The main advantages of sensorless control technique for BLDC motors is that it is cheap and reliable. In this method the rotor position is estimated using back emf zero crossing detection method. Back emf voltage is directly proportional to the speed of the motor.

In this work fuzzy logic based sensor less control technique is employed for speed control of BLDC motor. Wide speed range operation, high starting torque and smooth speed control are the advantages of this technique[13]. MATLAB based simulation studies is used to analyze the fuzzy logic speed controlled BLDC system. 
ISSN No:-2456-2165

\section{FOUR SWITCH INVERTER DRIVE FOR BLDC MOTOR}

Figure 1 shows the circuit diagram of a four switch inverter fed BLDC Motor. This drive circuit is derived from the six switch inverter circuit by replacing two switches with capacitors. This system is a low cost one due to reduced number of switches. The four switch BLDC motor drive consists of four switches $S_{1}, S_{2}, S_{3}$ and $S_{4}$ and DC link capacitors. The $\mathrm{a}$ and $\mathrm{b}$ phases of the motor are connected to the two legs of the four switch inverter and the $\mathrm{c}$ phase is connected to the mid- point of two DC link capacitors $\mathrm{C} 1$ and $\mathrm{C} 2$ having equal capacitance.

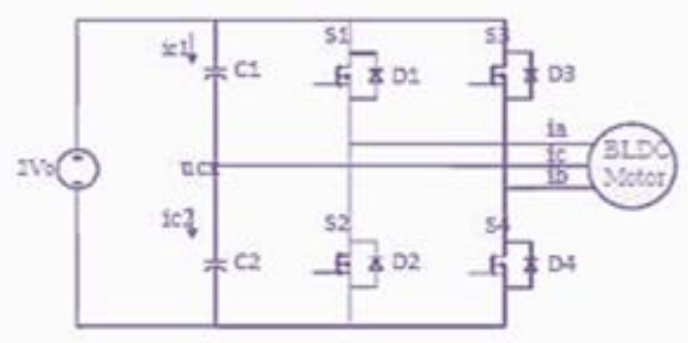

Fig 1:- Circuit diagram of four switch inverter

Figure 2 shows the modes of operation of four switch BLDC motor. Two phases conduct at a time and the remaining phase does not conduct. Only one switch isconducted inmodes1,3,4and6whiletwoswitches conducts inmodes 2 and5. From the connection diagram it is clear that a and $b$ phases are controllable and c phase is not. For BLDC motor, low ripple torque and low noise operation can be achieved when their phase currents have quasi-square waveform. The switching sequence of a four switch converter is shown in Table1

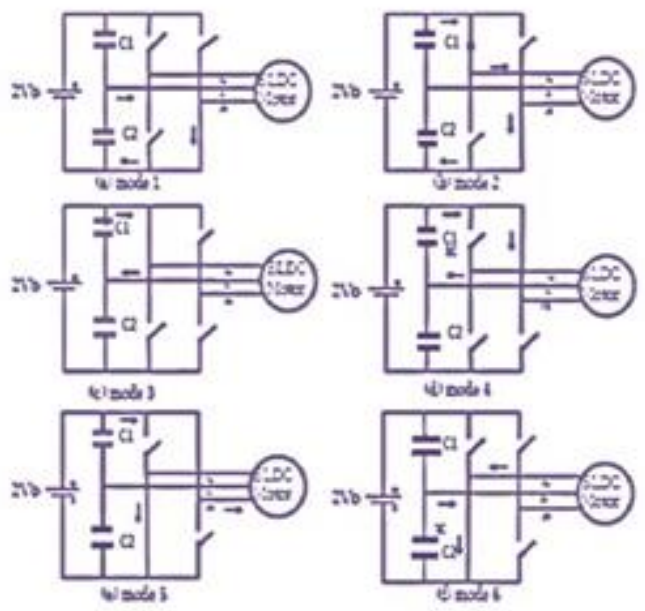

Fig 2:- Modes of operation of a four switch inverter

\begin{tabular}{|c|c|c|c|}
\hline Modes & $\begin{array}{c}\text { Switching } \\
\text { devices }\end{array}$ & Phases(Active) & Phases(silent) \\
\hline $1^{\text {st }}$ mode & $\mathrm{S}_{4}$ & $\mathrm{~b}, \mathrm{c}$ & $\mathrm{a}$ \\
\hline $2^{\text {nd }}$ mode & $\mathrm{S}_{1} \& \mathrm{~S}_{4}$ & $\mathrm{a}, \mathrm{b}$ & $\mathrm{c}$ \\
\hline $3^{\text {rd }}$ mode & $\mathrm{S}_{1}$ & $\mathrm{a}, \mathrm{c}$ & $\mathrm{b}$ \\
\hline $4^{\text {th }}$ mode & $\mathrm{S}_{3}$ & $\mathrm{~b}, \mathrm{c}$ & $\mathrm{a}$ \\
\hline $5^{\text {th }}$ mode & $\mathrm{S}_{2} \& \mathrm{~S}_{3}$ & $\mathrm{a}, \mathrm{b}$ & $\mathrm{c}$ \\
\hline $6^{\text {th }}$ mode & $\mathrm{S}_{2}$ & $\mathrm{a}, \mathrm{c}$ & $\mathrm{b}$ \\
\hline
\end{tabular}

Table 1:- Switching sequences for four switch converter

\section{SENSORLESS CONTROL OF FSTPI FEDBLDC MOTOR}

There are many control techniques for sensorless control of BLDC Motors. One of such method is backemf based position sensing. Another method which requires high speed processors, does position approximation using various motor parameters. As the second method is completely costly the first method is most commonly used.

The method that employs terminal voltage detection is commonly used for certain low cost industrial applications that doesnot require rigorous speed control. The Back EMF waveform is in trapezoidal shape and for a BLDC Motor it cannot be measured directly. Rotor position is estimated using zero crossing detection method employed with the help of a comparator circuit. In the conventional method,the back EMF waveforms of unexcited phase is analysed to detect the instant at which it crosses zero. The point of current commutation is determined by the Zero Crossing point (ZCP) of back emf and is estimated by shifting $30^{\circ}$ from ZCP. Only two phases conduct at a time and each phase conducts for 120electrical degrees. Back emf waveform with zero crossing point $(\mathrm{ZCP})$ is shown in figure 3 .

The condition for generation of maximum torque is that the commutation of inverter must occur every $60^{\circ}$ by sensing ZCP of back emf. This ensures that current is in phase with back emf. Also inorder to identify ZCP's the terminal voltage of floating phase should be passed through a low pass filter. Table 2 shows the sequence of commutation when back emf method is used.

The significant drawback of ZCP method is that the performance gets effected for a wider speed range. Also if the terminal voltage of floating phase is affected by noise,then it would become difficult to obtain the switching signals at lower speeds. 


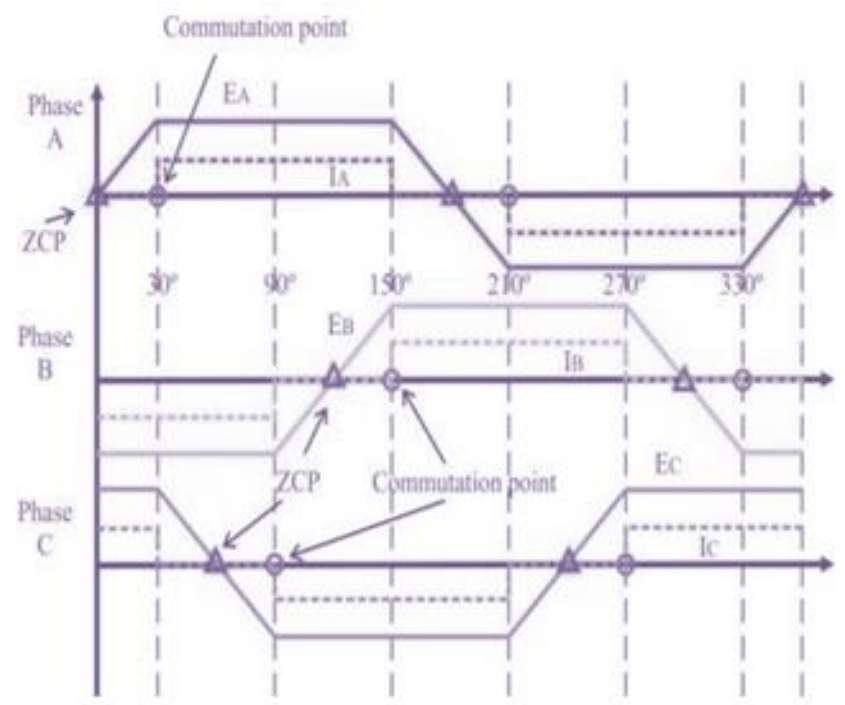

Fig 3:- Zero crossing points of the back EMF and phase current commutation points

\begin{tabular}{|c|c|c|c|c|c|c|c|}
\hline Modes & $\mathrm{E}_{\mathrm{n}}$ & $\mathrm{E}_{\mathrm{b}}$ & $\mathrm{E}_{\mathrm{c}}$ & $\mathrm{S}_{1}$ & $\mathrm{~S}_{2}$ & $\mathrm{~S}_{3}$ & $\mathrm{~S}_{4}$ \\
\hline Mode 1 & 0 & -1 & +1 & 0 & 0 & 0 & 1 \\
\hline Mode 2 & +1 & -1 & 0 & 1 & 0 & 0 & 1 \\
\hline Mode 3 & +1 & 0 & -1 & 1 & 0 & 0 & 0 \\
\hline Mode 4 & 0 & +1 & -1 & 0 & 0 & 1 & 0 \\
\hline Mode 5 & -1 & +1 & 0 & 0 & 1 & 1 & 0 \\
\hline Mode 6 & -1 & 0 & +1 & 0 & 1 & 0 & 0 \\
\hline
\end{tabular}

Table 2: Commutation sequence in Back emf difference estimation

\section{IV.DESIGN OF FUZZY LOGIC CONTROLLER(FLC)}

Fuzzy logic control is carried out by the principles of Linguistic variables. Like other methods it doesnot need complex numerical calculations. FLC is the most productive and simple to control a system. Fuzzy logic control depends on the Fuzzy set theory. Figure 4 shows the block diagram of a fuzzy logic controller.

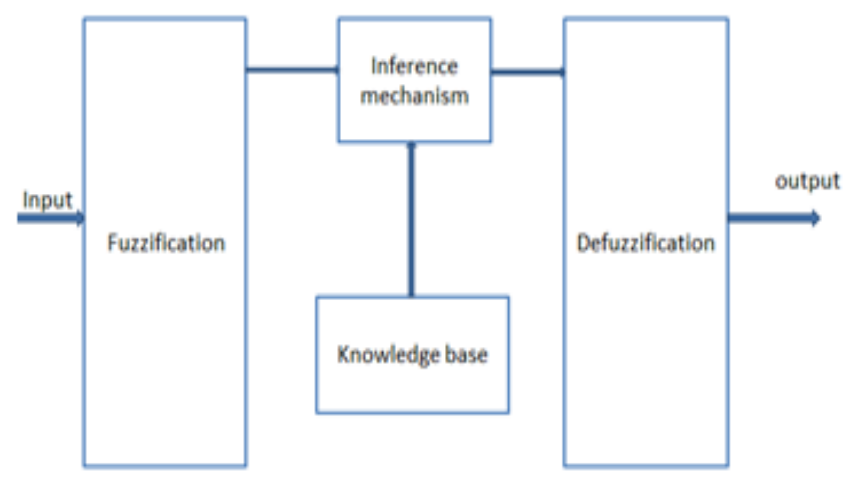

Fig 4 :-Fuzzy logic Controller
Every element in fuzzy set theory will have a degree of membership associated with any particular set. Fuzzy sets resembles classical but they does not have sharper boundaries. Main three components for a Fuzzy Logic controller (FLC) are Fuzzification, fuzzy Rule base and interfacing engine and Defuzzification.

Initial step in the fuzzy logic controller design is to identify the state variables that can effectively control the system. The chosen input state variables are passed through the fuzzification block. The numerical inputs are then converted to fuzzy linguistic variables as fuzzy rules can only work with fuzzy inputs. The process by which a numerical state variable converted into a fuzzy input linguistic variable is known as Fuzzification. The graphical representation of the degree of belonging of an element to the fuzzy set is known as a membership function. According to the requirement, different membership functions can be used for the input and output. There are two methods for a Fuzzy inference. First one is the Mamdani method which is commonly used and

The other one is Sugeno method. Mamdani is being employed here. Defuzzification is the converse of Fuzzification. The input linguistic variable consists of error and change in error whereas change in duty cycle is the output linguistic variable.

The difference between the reference speed and actual speed is the error while the difference between the present error and previous error is the change in error. Output can be either positive or negative. In order to determine the new duty cycle it is added to the existing duty-cycle. The linguistic terms are commonly expressed in the form of logical implications, such as If-Then rules. These rules explains a range of values known as fuzzy membership functions that can be in different shapes such as bell, triangular or trapezoid. Here seven subsets are used varying from Negative Big (NB) to Positive Big (PB) which are assigned to the input and output linguistic variables. Each subset has a triangular membership function to give a set of seven membership functions for each fuzzy variable. Negative Big (NB), Negative Medium(NM), Negative Small (NS), Zero (Z), Positive Small (PS), Positive Medium(PM) and Positive Big (PB) are the chosen linguistic terms.

Inorder to get sufficient back EMF magnitude the motor is being operated at 120 degree conduction mode. Sensed speed of the motor is compared with reference speed to generate the error signal. The error signal is fed to the fuzzy controller.

The fuzzy controller output value is used to produce the PWM signals in a closed loop mode. For PWM generation this value is used as the reference. Figure 5 shows the block diagram of closed loop control of BLDC motor drive using FLC. Fuzzy Associative Memory (FAM) is shown in Table 3. The FLC is analyzed using MATLABFIS Editor as shown in figure 6. 


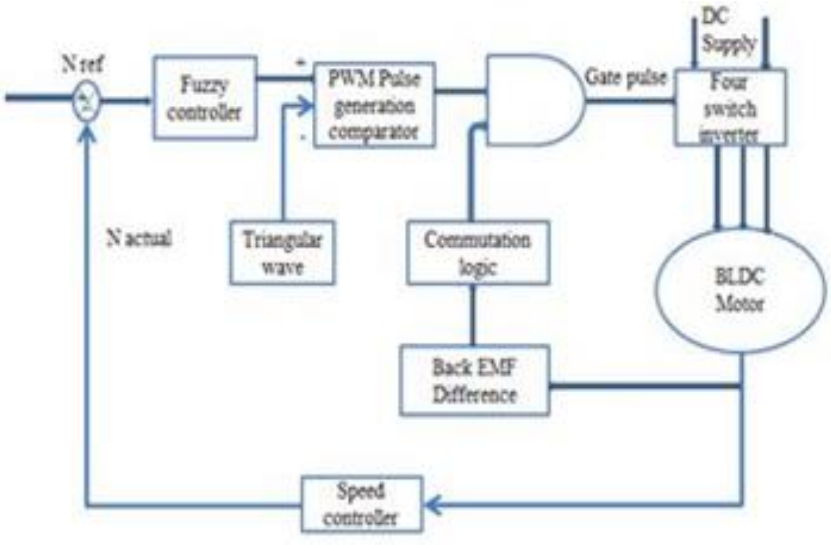

Fig 5:- Block diagram of closed loop control of BLDC motor drive.

\begin{tabular}{|c|c|c|c|c|c|c|c|}
\hline \multirow{2}{*}{$\begin{array}{c}\text { Change } \\
\text { in error }\end{array}$} & \multicolumn{7}{|c|}{ Error } \\
\cline { 2 - 8 } & $\mathrm{NB}$ & $\mathrm{NM}$ & $\mathrm{NS}$ & $\mathrm{Z}$ & $\mathrm{PS}$ & $\mathrm{PM}$ & $\mathrm{PB}$ \\
\hline $\mathrm{NB}$ & $\mathrm{NB}$ & $\mathrm{NB}$ & $\mathrm{NB}$ & $\mathrm{NB}$ & $\mathrm{NM}$ & $\mathrm{NS}$ & $\mathrm{Z}$ \\
\hline $\mathrm{NM}$ & $\mathrm{NB}$ & $\mathrm{NB}$ & $\mathrm{NB}$ & $\mathrm{NM}$ & $\mathrm{NS}$ & $Z$ & $\mathrm{PS}$ \\
\hline $\mathrm{NS}$ & $\mathrm{NB}$ & $\mathrm{NB}$ & $\mathrm{NM}$ & $\mathrm{NS}$ & $Z$ & $\mathrm{PS}$ & $\mathrm{PM}$ \\
\hline$Z$ & $\mathrm{NB}$ & $\mathrm{NM}$ & $\mathrm{NS}$ & $\mathrm{Z}$ & $\mathrm{PS}$ & $\mathrm{PM}$ & $\mathrm{PB}$ \\
\hline $\mathrm{PS}$ & $\mathrm{NM}$ & $\mathrm{NS}$ & $\mathrm{Z}$ & $\mathrm{PS}$ & $\mathrm{PM}$ & $\mathrm{PB}$ & $\mathrm{PB}$ \\
\hline $\mathrm{PM}$ & $\mathrm{NS}$ & $\mathrm{Z}$ & $\mathrm{PS}$ & $\mathrm{PM}$ & $\mathrm{PB}$ & $\mathrm{PB}$ & $\mathrm{PB}$ \\
\hline $\mathrm{PB}$ & $\mathrm{Z}$ & $\mathrm{PS}$ & $\mathrm{PM}$ & $\mathrm{PB}$ & $\mathrm{PB}$ & $\mathrm{PB}$ & $\mathrm{PB}$ \\
\hline
\end{tabular}

Table 3:- Fuzzy Associative Memory (FAM)

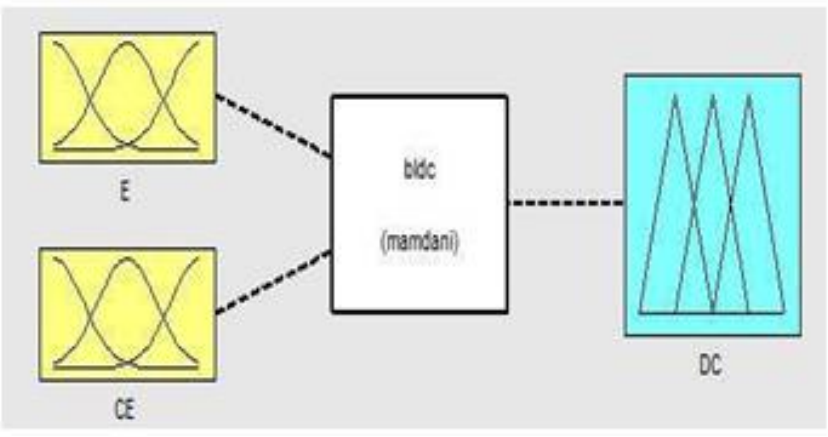

Fig 6:-FIS editor for speed control of BLDC motor

\section{V.SIMULATION AND RESULTS}

The simulation of the four-switch Brushless DC Motor system using fuzzy controller was carried out using MATLAB Simulink and waveforms were plotted. The complete SIMULINK model of a four switch BLDC motor using Fuzzy controller is shown in figure 7 and Table 4 gives the simulation parameters. The omponents used in closed loop BLDC motor drive system are BLDC motor, four switch inverter, back EMF difference calculation block, fuzzy controller, PWM generator block and commutation logic block.

Fuzzy controller determines and controls the overall performance of the closed loop system. The inputs used in the controller are error and change in error as shown in figure 8 and 9 respectively,themembership function of the output of fuzzy and its rules are used in
MATLAB/Simulink model and is shown in figure 10 and figure 11 The Fuzzy rule viewer used in MATLAB model is shown in figure 12 .

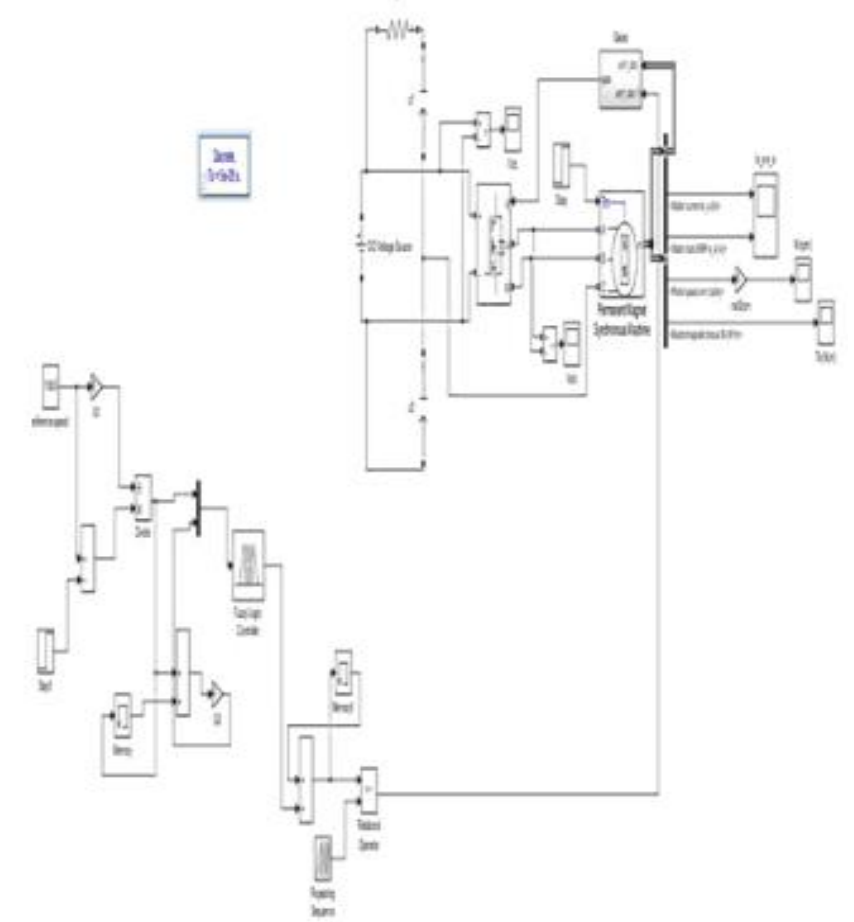

Fig 7:- Simulation model of four switch bldc motor using Fuzzy controller

\begin{tabular}{|c|c|}
\hline Number of phases & $\mathbf{3}$ \\
\hline Number of poles(p) & 4 \\
\hline Rated speed & $3000 \mathrm{rpm}$ \\
\hline Rated current & $5 \mathrm{~A}$ \\
\hline Rated voltage & $24 \mathrm{~V}$ \\
\hline Per phase resistance(R) & $0.57 \mathrm{ohm}$ \\
\hline Inductance(L) & $1.5 \mathrm{mH}$ \\
\hline Moment of Inertia(J) & 0.0000023 \\
\hline Rated Torque(T) & $0.42 \mathrm{Nm}$ \\
\hline Torque constant & $0.082 \mathrm{Nm}$ \\
\hline
\end{tabular}

Table 4:- Motor Specification

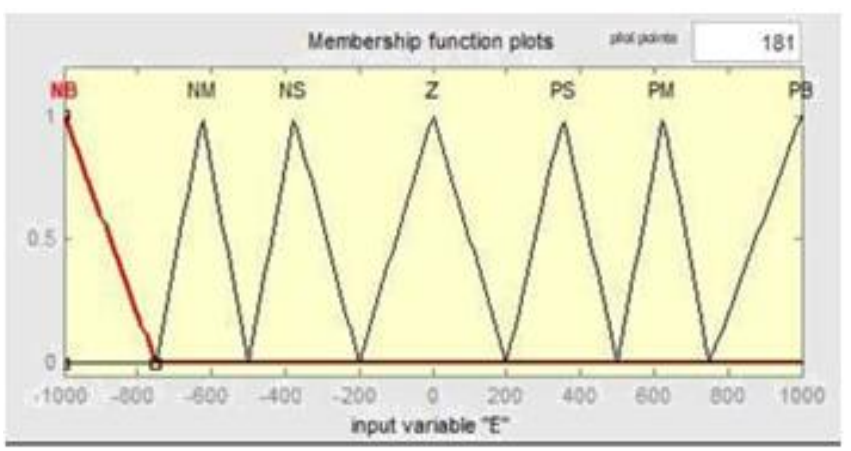

Fig 8:- Fuzzy membership functions of input error 


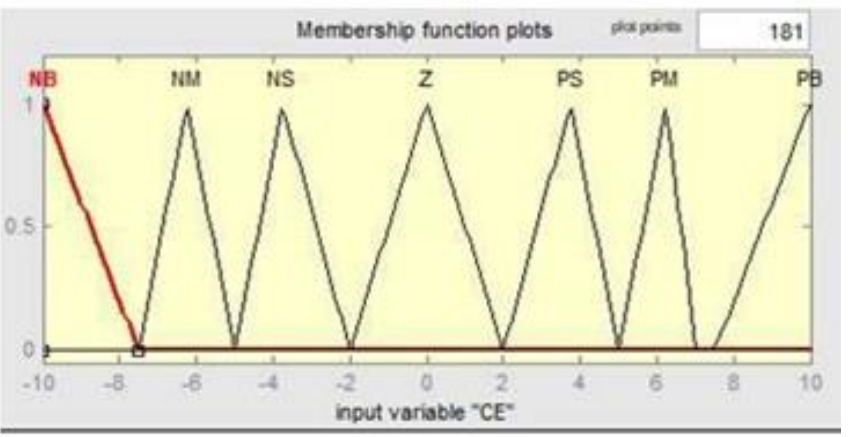

Fig 9:- Fuzzy membership functions of input change in error

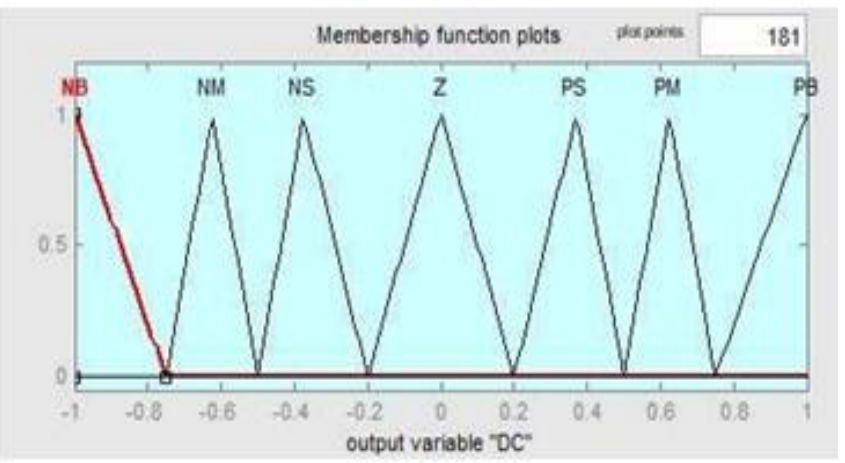

Fig 10:-Fuzzy membership functions of output duty cycle

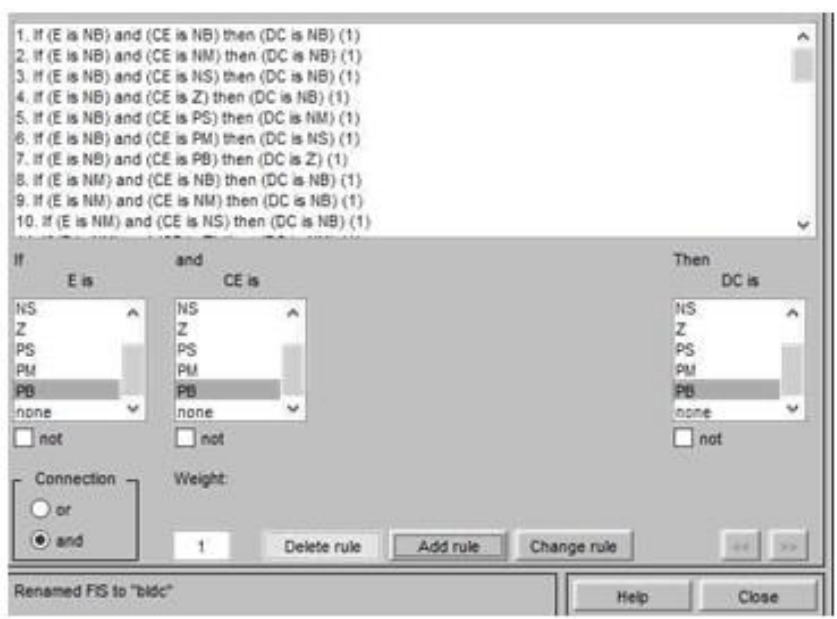

Fig 11:- Fuzzy rules used in MATLAB -Simulink model

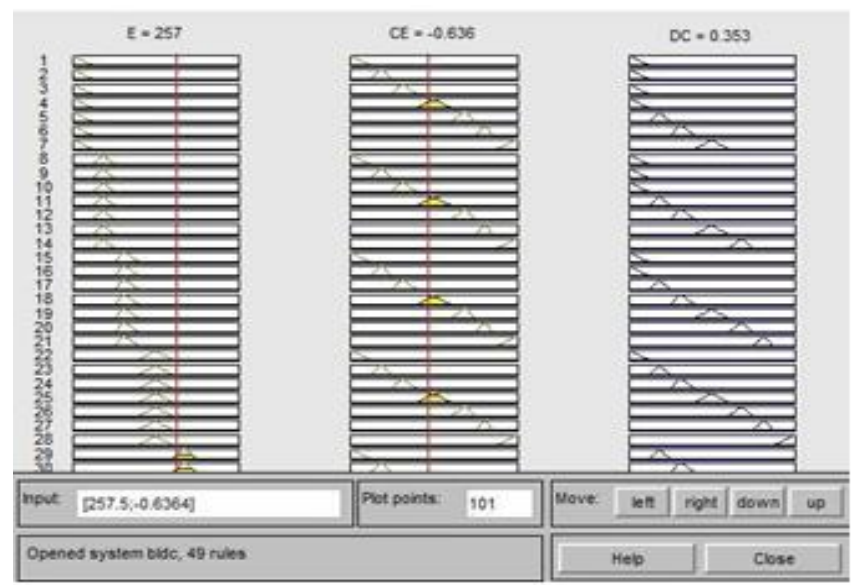

Fig 12:- Fuzzy ruleviwer used in MATLAB-Simulink model
The switching pulse of a four switch inverter is shown in figure 13.The line to line voltage is shown in figure 14. Stator current and Back EMF at reference speed of 1000rpm is shown in figure 15 and 16 respectively. The stator current has a quasisquarewaveform.

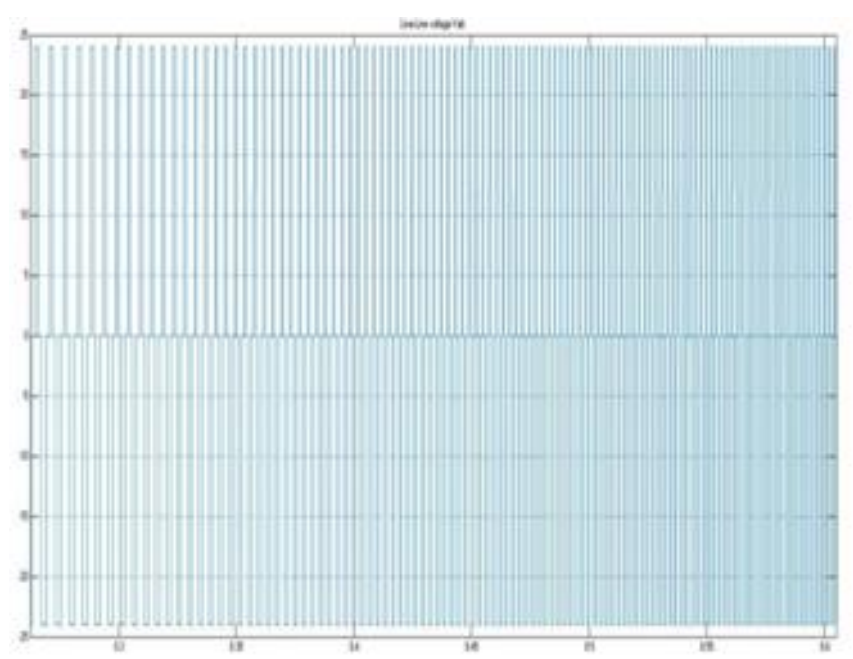

Fig 13:-Switching pulse of a four switch inverter

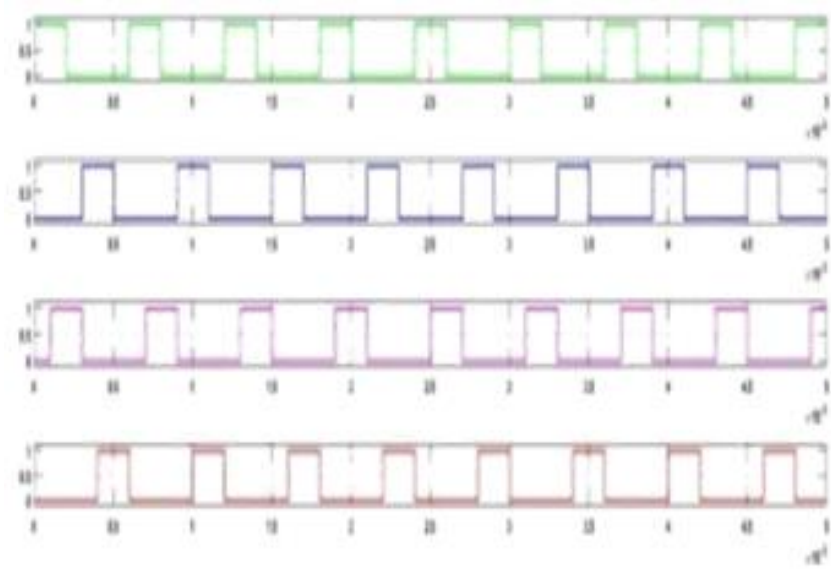

Fig 14:-shows the line to line voltage simulation waveform

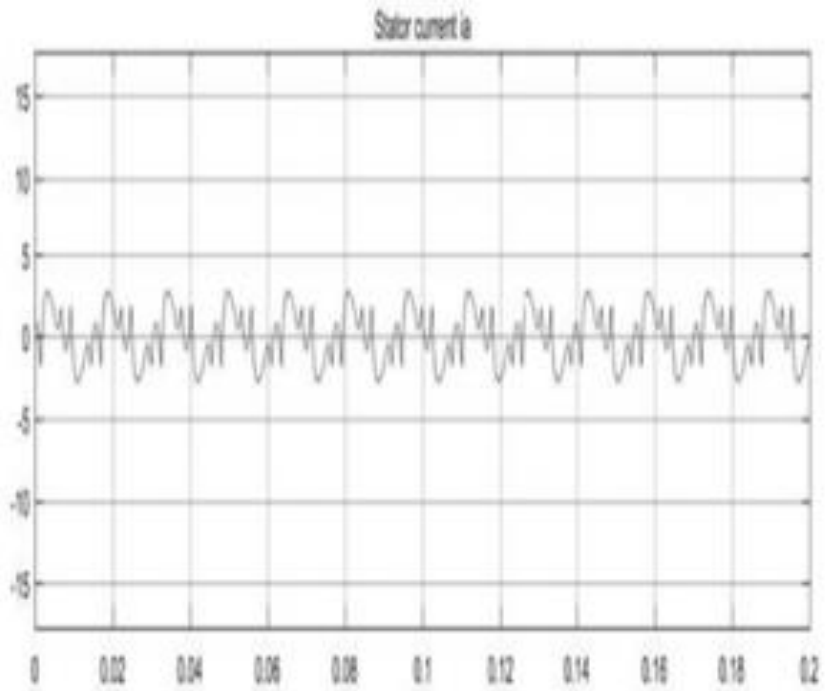

Fig 15:-Stator current simulation waveform 


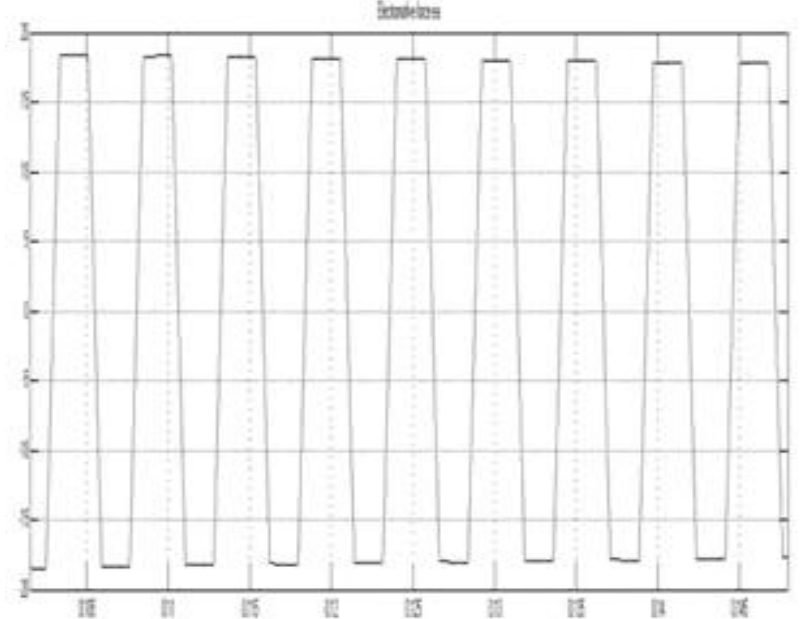

Fig 16:-Back EMF simulation waveform

The torque output is given in figure 17. Figure 18 shows the speed response of the system with change in load. Here reference speed is kept constant as $1000 \mathrm{rpm}$ and the load torque is being varied. Figure 19 and 20 shows the speed response of the system with linearly increase and decrease in the load respectively. Its speed responses are satisfactory and optimum.

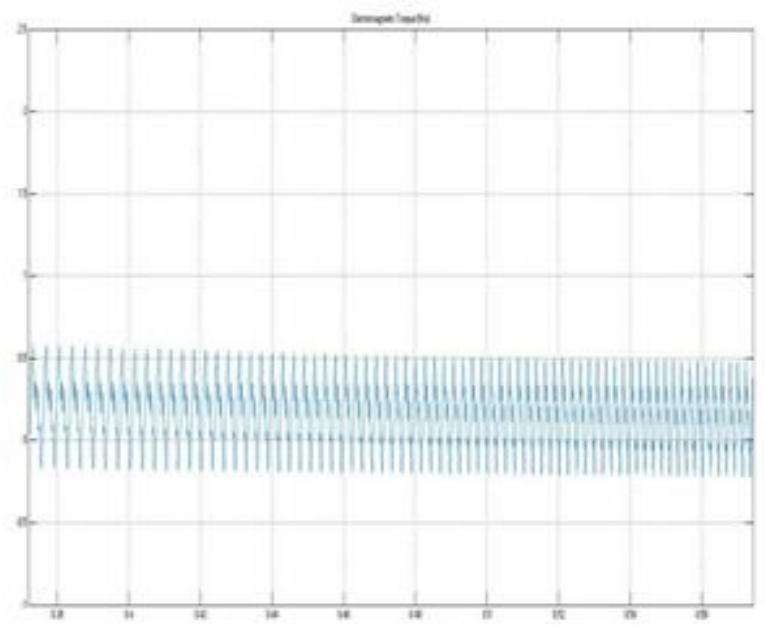

Fig 17:- Electromagnetic Torque simulation waveform
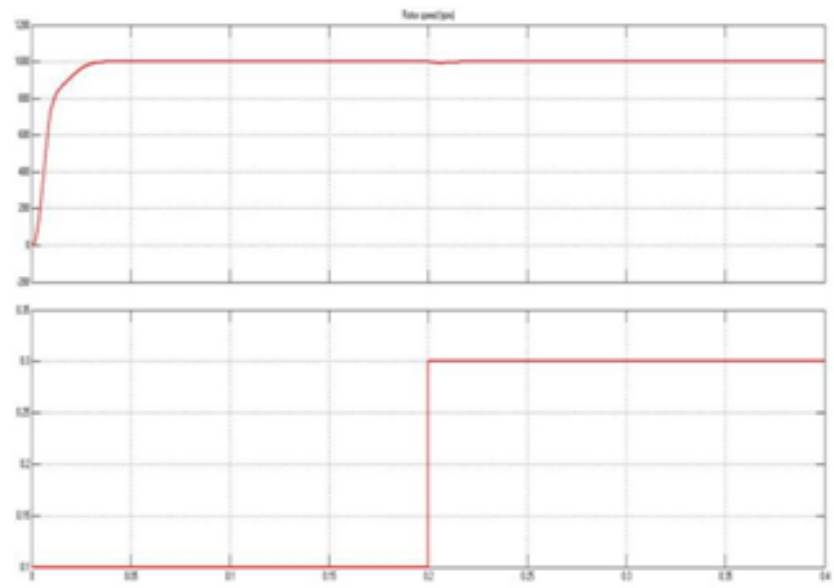

Fig 18:- Speed simulation waveform
A Four switch BLDC Motor in open loop was simulated and speed waveform was plotted by changing load. Speed response is shown with the change in load. Figure 21 shows the speed response of a Four switch BLDC motor in Open Loop. From speed time waveform it can be seen that when there is a load change the speed reduces.From the simulation results, it can be noted that that sensor-less technique by using back EMF difference provides good response and can be built by using high performance controllers without using filters.
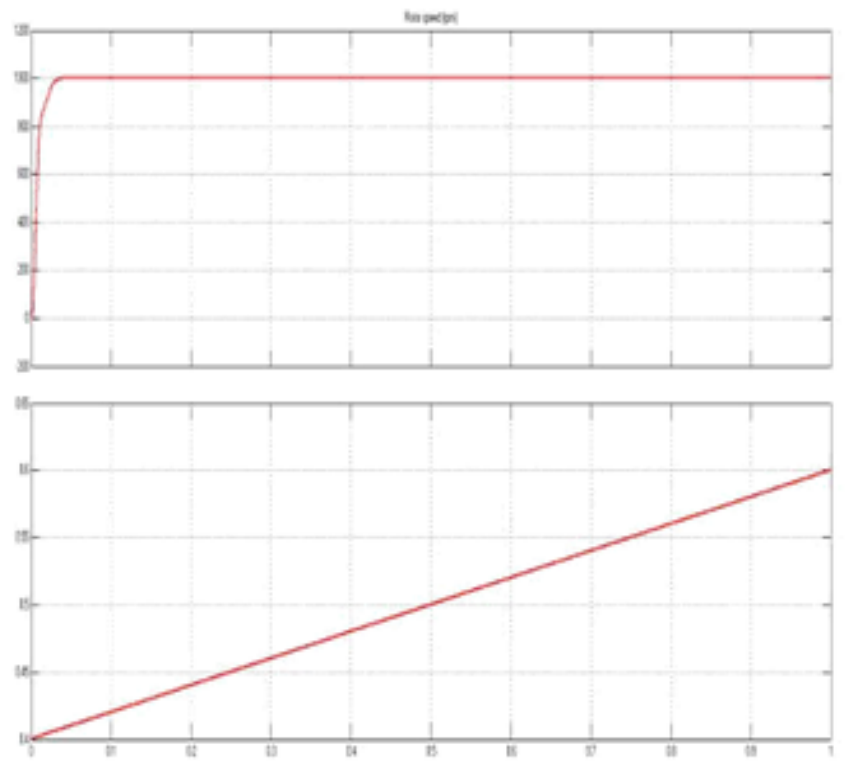

Fig 19:-Motor speed waveform with linearly increasing load
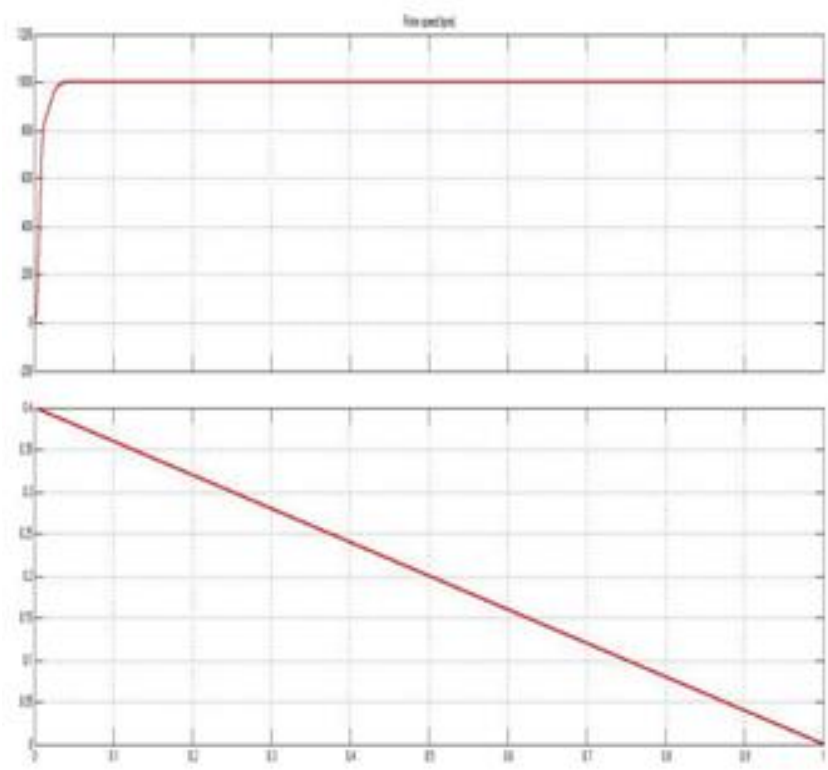

Fig 20:-Motor speed waveform with linearly decreasing load 


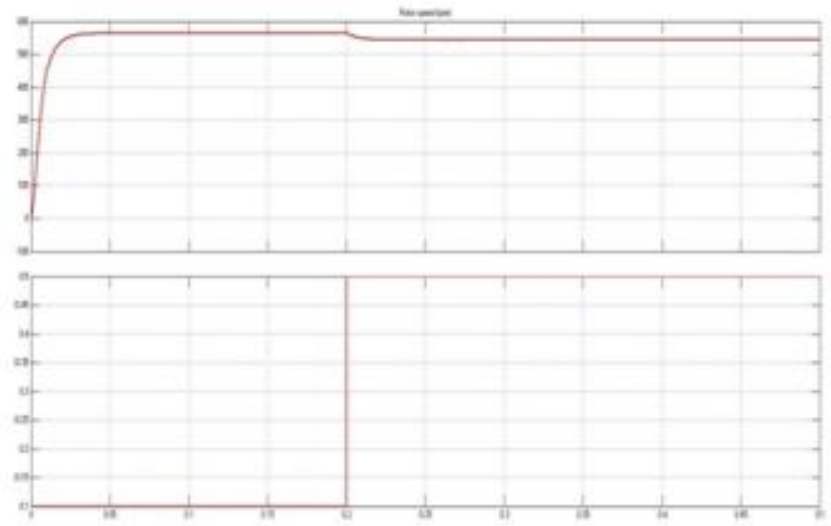

Fig 21: Motor speed waveform of an open loop Four switch BLDC Motor

\section{VI.CONCLUSION}

In this work a fuzzy controller based four switch inverter fed sensor less BLDC drive was analyzed. The open loop and closed loop controls of Four switch BLDC motor are pre-sented. It is observed that the speed changes with change in load in the open loop system. The speed is regulated in the closed loop system. This low cost system is used to detect the rotor position by using back EMF difference method. Reduced number of switches in the inverter topology adds to the advantage of reduced conduction and switching losses. This drive eliminates the need for taking motor neutral potential and has no complex delay circuit. It is used in low cost industrial and household applications. Fuzzy logic controller was employed for closed loop speed control of sensor less BLDC motor and the performance was analyzed using MATLAB software. The back emf, line to line voltages, torque and speed wave-forms of the closed loop BLDC motor system were plotted and the motor performance was found satisfactory.

\section{REFERENCES}

[1]. SreeramK, "Design of Fuzzy Logic Controller for Speed Control of Sensorless BLDC Motor Drive" 2018 International Conference on Control, Power, Communication and Computing Technologies (ICCPCCT)

[2]. Reshma K M, T. B. Isha, “ Back-EMF Based Sensorless Speed Control of Four Switch BLDC Motor Drive" 2018 International Conference on Control, Power, Communication and Computing Technologies (ICCPCCT).

[3]. Geethu James, Prof. K Radhakrishnan, Mrs.Jaya B M, ," Four Switch BLDC Motor Drive.," International Journal of Advanced Research in Electrical, Electronics and Instrumentation Engineering Vol. 2, Special Issue 1, December 2013.

[4]. Changliang Xia, Zhiqiang Li, and Tingna Shi, "A Control Strategy for Four-Switch Three-Phase Brushless DC Motor Using Single Current Sensor," IEEE Transactions On Industrial Electronics, Vol. 56, No. 6, June 2009.
[5]. G. J. Su and W. McKeever, "Low-cost sensorless control of brushless DC motors with improved speed range," IEEE Trans. Power Electron., vol. 19, no. 2, pp. 296-302, Mar. 2004.

[6]. V. P. Sidharthan, P. Suyampulingam and K. Vijith, "Brushless DC motor driven plug in electric vehicle," International Journal of Applied Engineering Research, vol. 10, pp. 3420-3424, 2015.

[7]. 7. K.Rajashekara, A.Kawamura, et al, "Sensorless Control of AC Motor Drivers, IEEE presses, 1996.

[8]. GeethuZacharia, AnnaiRaina, ,"A Survey on Back EMF Sensing Methods for Sensorless Brushless DC Motor Drives," International Journal of Emerging Trends in Engineering Research Volume 2, No.2, February 2014.

[9]. J.-H. Lee, S.-C. Ahn, and D.-S. Hyun,"A BLDCM drive with trapezoidal back EMF using four-switch three phase inverter," in Conf. Rec. IEEE IAS Annu. Meeting, vol. 3, pp. 1705-1709, 2000.

[10]. Jibin M Varghese , Jaya B, Justin Baby, ,“ PI tuning control of Four Switch Three Phase Brushless DC Motor," International Conference on Signal, Image Processing and Applications in 2011.

[11]. J. Malarvizhi, Dr. S. U. Prabha, ,Direct Torque Control of B4-Inverter Fed BLDC otor using Fuzzy Logic Controller," International Journal of Engineering Research \& Technology (IJERT) Vol. 3 Issue 12, December-2014

[12]. P. BharathLakshman Kumar, P. Chandra Sekhar, ,“ Control of Four Switch Inverter Fed BLDC otor Using Fuzzy Logic," International Journal of Advanced Research in Science,Engineering and TechnologyVol. 1, Issue 5 , December 2014.

[13]. E. Kaliyappan and C. Chellamuthu, "A simple sensorless control technique for PMBLDC motor using back EMF zero crossing," European journal of scientist research, vol. 60 , pp. $365-378,2$ 